\title{
Deregulating Medical Practice in New Zealand: Achievable and Desirable?
}

\author{
David Stewart and Hamish Stewart
}

$\mathrm{O}$ CCUPATIONAL regulation of medical practitioners in New Zealand, as in Australia, has tended to develop along the lines of traditional British and North American models, with certification or licensing boards established by parliamentary statute. These boards, which are usually controlled by the profession itself, regulate entry to medical practice and have considerable disciplinary powers. The licensing regime so established places severe restrictions upon those seeking to offer health-care services to persons in need, and thereby reduces both the total amount and the variety of such services available in the market (Friedman, 1962). Until relatively recently, there had been little questioning in New Zealand of the merits of this traditional approach because it was thought to benefit the public. However, following the advent of the 1993 health sector reforms, awareness of the costs of professional regulation has increased. The government has recently indicated that it intends to review the present arrangements (Peters, 1998).

\section{Public Requirements}

The way the current system of regulation has developed reflects the demands on a health system serving people who are usually anxious and frequently vulnerable at the time of seeking access to services. The vulnerability of the patient relates not only to the dependent status caused by the illness, injury or disability, but, more convincingly, to uncertainty about the nature and possible consequences of the illness and the risk of serious harm should the care be incompetent. Because of these concerns, and as a result of the politicisation of hcalth care, the view has emerged that health care is special and accordingly cannot be left to the market, so justifying government intervention in both the funding and the regulation of health-care providers (Arrow, 1963; Evans, 1984; Epstein, 1996a; Grcen, 1996).

This case for regulating medical practice is most convincingly built upon the argument of asymmetry of knowledge, which may affect the patient in two ways: how to know which doctors have the appropriate qualifications and expertise being sought in a specific circumstance, and how to know which doctors to trust when

David Stewart is Assistant Vice-Chancellor (Health Sciences) at The University of Otago, and a Director of Healthlink South and of HealthCare Otago. Hamish Stewart is Managing Director of Frost Capital Europe, a London-based investment merchant bank. 
treatment is being offered or given. A patient seeking treatment will normally wish to consult a medical practitioner who has well recognised and conventional qualifications appropriate to the particular services being sought. People may from time to time seek advice and help from practitioners who do not hold generally recognised conventional qualifications; but most would wish to do so with an understanding of the nature of the qualifications and expertise claimed by any such practitioner. The value to the public of information concerning the qualifications and expertise of practitioners is generally recognised, as is that of its certification by a reputable independent agency.

Even when certified information about qualifications and expertise is provided, the asymmetry problems are not fully resolved. The further issue for the patient is whether to trust and accept the advice being given by the doctor, particularly in the context of a possible pecuniary interest of that doctor in the advice being given. This is, of course, an issue in any commercial transaction, but there is a widespread view that patients are more vulnerable in medical consultations than customers generally are in their purchases of goods and services. This view is more valid when a patient has symptoms or disabilities not previously experienced, and has little understanding of the malady concerned. There are also small but appreciable risks of an adverse outcome from treatment, and of exploitation by an unscrupulous practitioner.

However, the traditional method of addressing the quality issues that asymmetry raises, namely, licensing of medical practice, increases the risks of diminished accessibility to services, creates barriers to innovation and leads to an unresponsive medical profession. The disciplinary powers granted to the licensing body also create a conflict of interest for the profession. An alternative approach to resolving this asymmetry would be through the use of agents (such as general practitioners or insurers) acting on behalf of patients seeking a second opinion or specialist services (Epstein, 1996a).

\section{Failure of the Current Regime}

The current arrangements for licensing medical practitioners are almost entirely aimed at ensuring the quality of those services that are provided, often at the cost of reduced accessibility. The approach is to impose stringent criteria for entry to the profession and to strongly delineate the tasks carried out by allied professionals and by different specialists within the medical profession. Although the Medical Council exercises a disciplinary function, the reality in New Zealand is that after meeting the entry criteria for specialist medical practice (which now includes family medicine or so-called general practice) through training and examination, doctors are essentially licensed for their working lives. These entry requirements do generally ensure the ability and expertise of doctors, but they reduce their number and hence access to medical services, and may fail to ensure that competence is maintained during a working life that often stretches beyond 40 years. Further, the high barriers between disciplines reduce innovative practices to meet specific needs: for example, the prescription of certain classes of drugs by nurses, the multiskilling of surgeons for rural 
practice, or the recruitment of multiskilled and culturally appropriate health workers to meet basic health care needs of Maori and Pacific Islanders.

In New Zealand, the adverse impact of these barriers is currently most apparent in the shortage of medical specialists in some disciplines, particularly psychiatry and orthopaedic surgery. The shortage of psychiatrists and other mental health workers is a major public issue at a time when the workforce need for trained mental health workers is increasing as a result of de-institutionalisation of psychiatric care and increasing substance abuse, especially among the young and the mentally ill. The government is committed to expanding publicly financed mental health services, but has been unable to do so, at least in part because of difficulties in recruiting psychiatrists. It is now more than 20 years since the need to increase the number of psychiatrists was recognised by targeted government funding of posts for psychiatry trainees, but a persistently high failure rate in the examination which represents the single route of qualification recognised by the Medical Councils in both Australia and New Zealand has perpetuated a shortage of psychiatrists in both countries.

The shortage of orthopaedic surgeons and some other surgical specialists is manifest through delays of between six and twelve weeks in obtaining an appointment to see a specialist in private practice, even for a patient who is considered to have an urgent problem. Emergencies (trauma, cancer) are effectively treated in the public hospitals, but there are long queues for all other conditions. It has also been suggested that incomes for some specialists may include a significant rent component resulting from a restriction in supply, a matter which has attracted the attention of the Commerce Commission. This shortage of surgical specialists is the direct consequence of restrictions on entry to the only recognised training program for surgeons in New Zealand, through limits imposed upon the accreditation of training posts by the College of Surgeons and its advisory bodies.

A further cause of public concern is the difficulty in recruiting and retaining general practitioners in rural areas, particularly in more remote South Island districts and in some smaller provincial towns. This situation persists despite concerns voiced by the Regional Health Authorities of over-supply of general practitioners in some metropolitan areas, notably some suburbs in Auckland and in Dunedin, and large numbers of foreign medical graduates seeking admission to the medical register in New Zealand. Clearly, the present licensing regime cannot be held fully responsible for this maldistribution, which has more to do with the fee-for-service approach to primary care subsidies and the ability of general practitioners to earn adequate incomes in city practice under present conditions; but it does prevent innovative solutions which might otherwise be found.

The historic approach to any dissatisfaction with these traditional arrangements has been to review the legislation and propose changes to the membership of the registration board established by that legislation. Experience in New Zealand suggests that such reviews may increase barriers to entry to the profession in question, preserve barriers to innovation and conflicts of interest, and provide only marginal benefits in the areas of information and indemnity (the Medical Practitioners Act 1995 is one such example). These reviews have not considered more radical re- 
form because of a presumption of the requirement for a statutory approach to occupational certification.

\section{Alternative Proposals}

Dissatisfaction with the present regime of occupational regulation in the health sector in New Zealand has led to a number of reviews of regulation of specified professional groups, usually in the context of a review of the pertinent legislation, from which a number of suggestions for change have emerged. These suggestions have generally been informed by models for other professional groups or by international practice (New Zealand Business Roundtable, 1998; Stewart, 1998).

Ontario and the Netherlands have recently brought all regulated health professions under the umbrella of a single act, with the possibility also of amalgamating the corresponding registration boards. The objectives are to break down barriers between professional groups and possibly to reduce conflicts of interest and barriers to entry, thereby allowing greater consumer choice of health care provider, more flexible use of health professionals and evolution of the professions in line with changing patterns of health care (Pew Health Professions Commission, 1995). It will take time to ascertain whether these objectives can be achieved in this way, but there must be some uncertainty as the approach does not address the fundamental issue, that of monopoly rights in the provision of certification information for the individual occupational groups covered.

An alternative approach recently taken up in both New Zealand and Australia is the explicit application of the provisions of competition legislation to professional practice. In New Zealand, the Commerce Act 1986 was amended in 1993 to apply to all providers of health or disability services, whether public or private, in the same way as it applies to other businesses. Similarly, in Australia the Competition Policy Reform Act 1995 amended the Trade Practices Act so as to extend its coverage to the professions. The objective of these measures was to limit the ability of individual professional groups to continue practices which substantially lessen competition in the market. However, in regard to medical practitioners this objective is frustrated in New Zealand as a result of the statutory powers granted to the Medical Council by the Medical Practitioners Act 1995. While these powers are retained by a monopoly body substantially under the control of the profession itself, progress to increase competition and reduce the prices of services by opening up entry to both general and specialist practice is likely to be limited, despite the best efforts of the Commerce Commission.

Another approach would be to permit the franchise of alternative registration boards with statutory powers, thus allowing contestability of certification with the existing regulatory agencies. This would clearly eliminate the present monopoly position of these agencies, thus reducing the ability of the professional groups to establish entry criteria at an inefficiently high level. But the regime required to regulate the franchising arrangements would in itself create costs and erect barriers,

\footnotetext{
We are indebted to an anonymous referee for this suggestion.
} 
thereby limiting the benefits.

All of the foregoing suggestions assume a continuation of statutory registration boards in some form or other. A more radical reform would involve the replacement of statutory provisions by voluntary arrangements for the certification of medical practitioners, as earlier suggested by Friedman (1962). There are a number of realistic approaches to such voluntary certification, ranging from certification by third party payers, employers of health professionals, credentialling institutions (generally hospitals or clinics) or indemnity insurers, to certification by independent rating agencies. There would be a great deal in common between all these approaches, because of the substantial degree of deregulation involved, and the possible absence of any statutory prescription about how certification should be achieved.

The remainder of this article is devoted to elaborating this model.

\section{A System of Deregulated Certification: Key Elements}

Establishing any truly deregulated system for the certification of health professionals, including medical practitioners, involves four key elements. These are:

- disclosure of specified information by any professional seeking to provide health care services. The information to be in the public domain would include name, qualifications with dates, business address, scope of practice, and current standing with both an independent certification authority and an indemnity insurer;

- contestability in certifying the information required by disclosure;

- minimal statutory compliances for health professionals covering only disclosure and the statutory compliances generally required of the business and private community; and

- liability for the consequences of failure to meet an acceptable standard of care (medical malpractice) to lie with the health care provider.

Each of these elements is discussed in detail below.

\section{Disclosure}

A requirement to disclose specified information is a minimal and low-cost provision for the protection of the public, and would provide equivalent information to that given by simple registration. The value of such information, however, would be greatly enhanced by its independent certification and, providing this certification were voluntary and contestable, it is likely that the additional cost would be acceptable. Independent certification by a reputable body would provide assurance to patients about the quality and standing of a practitioner's qualifications and exper- 
tise, and also about continuing competence were current standing with an indemnity insurer also fully disclosed and certified. Consideration would need to be given to whether there should also be public disclosure of all malpractice claims and disciplinary proccedings involving medical practitioners, as recently introduced for doctors in the United States (Mullan et al., 1992; Epstein, 1997).

There is a view that disclosure of information should be voluntary rather than compulsory. This approach would be consistent with the basic principle that voluntary arrangements should normally be preferred to compulsory ones on both moral and economic grounds, and be supported by the view that the consumer would be protected by his or her right to refuse to deal with any practitioner who failed to disclose essential information sought by a potential patient. It is also based upon an enlightened view of human nature and human abilities, which would have the consumer accept the responsibility of attending to his or her own best interests, and would acknowledge the capacity of the majority of the population, directly or through an agent of their own choosing, to do so at least as effectively as would a government agency (Epstein, 1996a).

However, in respect of health care services, the public in New Zealand has become accustomed to paternalistic arrangements (Green, 1996), and it is widely believed that to move directly to a completely voluntary system in such circumstances could expose too many patients to an unacceptable risk (Evans, 1984). This argument may be more justified in respect of health care services than of other services because of the intermittent and unpredictable incidence of serious illness or injury, the dependent state of a patient at the time of such illness or injury, and the risk of serious and potentially irremediable harm in the case of incompetent care.

Whether these fears are well-founded cannot be known, but, were change to be proposed, the strength of feeling on this matter among the public would be fuelled by professionals with a special interest in the status quo. Some compromise with truly liberal arrangements regarding disclosure of information may be a necessary minimum concession to gain the public and political support required to achieve deregulation of the kind being suggested here. There would be an expectation that as the public became aware of the benefits of deregulation and more confident in their ability to take a greater level of personal responsibility in the evaluation of their own health care, the need to retain compulsion in this matter could be reviewed.

\section{Contestability of Certification}

Any substantial deregulation of medical practice in New Zealand would necessarily involve the repeal of the Medical Practitioners Act 1995 and the abolition of the Medical Council of New Zealand as a statutory authority. The Medical Council presently holds a monopoly of certification of information concerning qualifications and of granting a licence to practise. As a minimum, deregulation would require these roles to be contestable.

There is no reason why the certification of information concerning the qualifications, expertise and continuing competence of medical practitioners should not be a contestable service. There certainly would be a strong market for information 
of this kind were the Medical Council of New Zealand to cease to exist. At least four options to meet this market come directly to mind. The first option would be for employers and credentialling bodies to take on the responsibility in-house. The second option would be for third-party payers to do this. However, in New Zealand such bodies are unlikely to achieve effective economies of scale in this activity, and are more likely to purchase the information from other providers. The third option would be for indemnity insurers to undertake this task, and in the absence of any alternative reliable sources of certification they would surely do so. But the most likely arrangement would be the establishment of one or more independent rating agencies to provide these services.

Such agencies would be very like medical councils, but without a monopoly or any statutory protection, and without any role in discipline. They would gather and evaluate information concerning qualifications, expertise and performance from practitioners, institutions, and insurers, and use this information to provide risk management advice, possibly in the form of a risk rating, to employers, credentialling bodies, third party payers, indemnity insurers and the public. Such risk rating would quickly gain acceptance for use by these various parties; and contestability would control costs and ensure an acceptable degree of reliability.

Contestable certification could give rise to concern about the probity of some independent certification agents. There could be a risk that agents may be willing to compromise certification standards on behalf of a client and thereby compromise the safety of that client's patients. Such a risk might be credible in the case of an agent without an established reputation, but would be hardly conceivable in respect of a nationally or internationally established agency with a reputation to preserve. Employers, third party payers and indemnity insurers would insist upon certification by reputable agents who could be held to account in the event of misadventure.

\section{Minimal Statutory Compliances}

Deregulation of health professional practice is unlikely to result in increased access and reduced costs if substantial statutory compliances remain in place in addition to those generally required of businesses and the community. There is increasing concern in New Zealand already about the impacts of statutory compliances and their effect on economic performance. An escalation of substitute regulations for consumer protection in the wake of medical deregulation would largely negate the benefits of this reform. This could be avoided only if the new arrangements for disclosure and certification of information and liability for medical malpractice provided appropriate safeguards for the public.

\section{Liability for Medical Malpractice}

Medical malpractice, sometimes called medical error, is defined as failure by a registered health professional to meet an acceptable standard of care. Medical malpractice does not necessarily result in an adverse outcome for the patient, and only a proportion of adverse outcomes are the result of medical malpractice. In consid- 
ering liability, it is essential to distinguish between adverse outcomes which occur despite entirely appropriate care, and those associated with malpractice.

Regarding the former, it is important to recognise that all medical treatment carries some risk, and adverse outcomes may result despite exemplary care. In these circumstances the risk appropriately lies with the patient as a trade-off against the expectation of benefit from the treatment, and the patient should accordingly accept liability. Because the risk of considerable loss and high costs is small but significant, it is properly covered by first-party indemnity insurance (Epstein, 1996b). However, second-party insurance cover by the health-care provider could be administratively more convenient, with the insurance premium set against the fees received for the services provided. The direct or indirect acceptance of this risk by the patient is a necessary feature of ethical medical practice.

However, when an adverse outcome results from medical malpractice, liability should clearly rest with the practitioner and/or provider who have failed to meet an acceptable standard of care. Normally all health care practitioners and institutional providers carry indemnity insurance cover to meet any claim resulting from alleged malpractice. This raises the question whether full insurance cover in the absence of a medical disciplinary regime may result in less risk-averse behaviour by medical practitioners, which might not be in the interests of their patients or their insurers. For patients, the concerns of the practitioner or provider for their reputation, as well as the generally high standards of ethical practice in New Zealand in the context of small communities, high literacy and considerable media interest in the quality of health care delivery, would offer some protection. Nevertheless, deregulation would inevitably place greater responsibility upon patients in their selection of providers of health care. $\Lambda$ s far as insurers are concerned, the well-established methods of reducing moral hazard, including liability covered by the insured to a threshold amount (excess or front-end deductible) and premiums based on claims history, are likely to be effective. The cost of this insurance, and consequently fees to patients, could rise following deregulation, but this would depend more upon the details of the indemnity regime for personal injury resulting from medical malpractice applying in the relevant jurisdiction (see below) and changes in the incidence of such injury, rather than upon deregulation as such.

In New Zealand, the indemnity arrangements for these adverse outcomes are complicated by the provisions for personal injury under the Accident Rehabilitation and Compensation Insurance Act 1992. This legislation provides indemnity against the costs of further treatment and rehabilitation, and specified compensation for permanent handicap and loss of income resulting from medical misadventure. For the purposes of this legislation, medical misadventure includes both medical error (medical malpractice) and medical mishap, which is defined as an adverse consequence of health professional treatment properly given when both the likelihood of this adverse consequence is rare (defined as less than 1 per cent) and the adverse consequence is severe.

The Accident Rehabilitation and Compensation Insurance Act prohibits a person from taking legal proceedings to recover damages in respect of personal injury 
covered by the Act. This provision, in effect, replaces tort law by contract arrangements for resolving indemnity claims in respect of personal injury (see Epstein, 1996b), including that resulting from medical misadventure. It also limits financial liability for medical misadventure in New Zealand, and is a major factor in constraining medical indemnity insurance costs in this country. While there is a general consensus that the overall benefits of this provision outweigh the costs, it protects incompetent health professionals from the financial consequences of their shortcomings and reduces the risk to their insurers. This effect seriously diminishes one major disincentive to incompetent practice, namely, the financial risk from litigation. If this risk were high, the premium for indemnity insurance would be correspondingly high, and in the extreme case insurance could be unobtainable. The present licensing regime protects indemnity insurers, including the Accident Rehabilitation and Compensation Insurance Corporation (ACC) in New Zealand, by excluding obviously incompetent practitioners. Abolition of licensing accordingly could have a major impact on indemnity, and no alternative regime would be sustainable if this issue were not effectively addressed prior to implementation.

There are a number of possible approaches to this problem. The simplest measure within the current legislation would be a more explicit experience rating for the ACC premiums of health professionals who contribute to the Medical Misadventure Account. In the first instance this could be indexed to an independent rating by a recognised rating agency, with a default premium for any practitioner unable to provide an acceptable rating. This measure, in any case, would be an essential preliminary if the Medical Misadventure Account were to be opened to private insurers or even self-insurance, as is occurring with the Employers' Account.

Probably a more effective measure would be to amend the present ACC legislation to permit the $A \mathrm{CC}$ or alternative insurer to recover all their indemnity costs from the liable practitioner in cases of medical error (medical malpractice). This would clearly transfer the liability for medical malpractice to the practitioner and that practitioner's indemnity insurer, while retaining the generally beneficial contractual approach of the ACC legislation to personal injury liability.

A third approach would be to exclude medical crror altogether from coverage by ACC legislation. In effect this would allow medical malpractice to be covered through indemnity insurance contracts held by the individual practitioner and by institutional health care providers, with common law tort remedies as the default provision.

Of these three approaches, a combination of the first and the second is likely to be favoured as providing an explicit and economical path for any person seeking a remedy that would meet the condition of requiring indemnity costs to rest with the liable practitioner. However, for this approach to be fully effective in assigning liability, it would be a precondition that indemnity insurance for medical malpractice be fully contestable (Epstein, 1996b), through opening the ACC Medical Misadventure Account to private insurers or to self-insurance. This contestability of insurance would provide the necessary incentives for insurers to recover their costs in any cases involving medical error. The third approach, removal of coverage for 
personal injury resulting from medical error from the ACC legislation, could increase the occurrence of unrewarding litigation, create incentives to hide medical malpractice, and result in escalating costs arising from tort actions.

If medical and other health professional practice were deregulated, section 5 of the Accident Rehabilitation and Compensation Insurance Act 1992 defining medical misadventure, would require review. This section, for the purposes of the Act, restricts the definition of both medical error and medical mishap, and thereby medical misadventure, to events associated with treatment by a registered health professional. A review of these definitions would be necessary to ensure that appropriate coverage under the Act would continue after deregulation. It is likely that insurers, whether $\mathrm{ACC}$ or private, would continue to require some form of reputable certification in order to protect their interests.

\section{Public Requirements: Would These Proposals Meet Them?}

We believe that the arrangements described in this article would adequately meet the needs of the public for information and assign liability for medical malpractice. In addition, they would offer the benefits generally associated with deregulation of any commercial activities through increased availability, improved quality and reduced costs. Specifically, abolishing the requirement for a licence to practise and allowing certification to become contestable could:

- provide opportunities for entry to practise to those currently excluded;

- permit multiskilling of the present health professional workforce, including an assumption by other practitioners of roles and tasks traditionally reserved to a specified occupational group; and

- enhance opportunities for health professionals with qualifications gained outside New Zealand and Australia to practise in these countries.

All these features would be in accordance with the overall direction of recent government policy in New Zealand, and with the desire of the public generally to have increased access to health care services.

The valid concern for the maintenance of quality and for safety considerations could be met by:

- a voluntary certification regime together with an acceptance by the patient of responsibility to ensure that any practitioner consulted were properly qualified;

- ensuring that liability for malpractice is properly borne by the practitioner, not by the state; and

- a likely conservative response of third-party funders and indemnity insurers to new entry of practitioners seeking to provide services. 
In addition, the incentives in the system described could ensure the continuing compctence and maintenance of standards by all doctors throughout their working lives, at least to the degree achieved under the present statutory regulations.

\section{Relevance for Other Occupational Groups}

The model elaborated here has been specifically developed in the context of the requirements for medical practice, for which protection of patients from personal injury or even death as a result of malpractice is the principal justification for statutory regulation. This same justification also applies in the practice of other health professionals, such as nurses, dentists, physiotherapists, pharmacists and optometrists, and this model equally could be adopted for those groups. Whether it appropriately could be extended to the regulation of other occupations, such as electricians or plumbers, about whom the safety of the public also is a primary concern, is less clear to us because of the requirements of the building and other statutory codes affecting these occupations, which lie outside our personal experience. Nevertheless, we believe that the general principles underlying the model could be applied to occupational regulation in gencral, including the regulation of occupations in law, insurance, banking and securities, to name only a few, for which the concern is the probity and accountability of the provider of services rather than the personal safety of the consumer. Indeed, these principles already generally apply in those occupations which are substantially deregulated, such as accountancy in New Zealand, in respect of which the public interest is protected by voluntary arrangements, together with the general requirements of legislation such as the Fair Trading Act 1986 and the obligations of 'caveat emptor'.

\section{References}

Arrow, K. (1963), 'Uncertainty and the Welfare Economics of Medical Care', American Economic Review 53: 941-73.

Epstein, R. (1996a), 'Why is Health Carc Special?', pp. 19-39 in R. Epstein, Back to Basics in the Health Carc Debate, New Zcaland Business Roundtable, Wellington.

(1996b), Accident Compensation: The Faulty Basis of No-fault and State Provision, New Zealand Business Roundtable, Wellington.

- (1997), Mortal Peril: Our Inalienable Right to Health Care?, Addison-Wesley, Reading, Massachusetts.

Evans, R. (1984), Strained Mercy: The Economics of Canadian Health Care, Butterworths, Toronto.

Friedman, M. (1962), Capitalism and Freedom, University of Chicago Press, Chicago.

Green, D. (1996), From Welfare State to Civil Society. Towards Welfare tuat Works in New Zealand, New Zealand Business Roundtable, Wellington.

New Zealand Business Roundtable (1998), 'Occupational Regulation in the Health Sector: A Commentary on Recent Papers and Reports', in Committee Advising on Professional Education (F. Holmes, chair), Occupational Regulation in the Health Sector, Wellington, New Zealand. 
Mullan, F., R. Politzer, C. Lewis, S. Bastacky, J. Rodak \& R. Harmon (1992), 'The National Practitioner Data Bank: Report from the First Year', Joumal of the American Medical Association 268; 73-9.

Peters, Hon. W. (1998), Budget Speech (14 May).

Pew Health Professions Commission (1995), Critical Challenges: Revitalising the Health Professions for the Twenty-First Century, quoted in Committee Advising on Professional Education (F. Holmes, chair), Occupational Regulation in the Health Sector, Wellington, 1998, p. 5.

Stewart, D. (1998), 'Occupational Regulation in the Health Sector: A Proposed New Regime', in Occupational Regulation in the Health Sector, Committee Advising on Professional Education, Wellington, New Zealand.

The authors wish to acknowledge constructive suggestions by the anonymous referees of this paper. 